\title{
STUDY OF CONTENT MANAGEMENT SYSTEMS JOOMLA AND DRUPAL
}

\author{
B V Wakode ${ }^{1}$, D N Chaudhari ${ }^{2}$ \\ ${ }^{1}$ Assistant Professor, IT Department, GCoE Amravati, Maharashtra, India, bhushan.wakode@gmail.com \\ ${ }^{2}$ Professor, CSE Department, JDIET Yavatmal, Maharashtra, India, dnchaudhari2007@rediffmail.com
}

\begin{abstract}
A content management system (CMS) is a software program that makes building and maintaining Web sites faster and easier. The system can automatically pull the content out and show it on the appropriate pages based on rules you set up in advance. There are several CMS available now a day's varying based on functionalities and platforms. The challenge in correctly implementing a CMS is both the author's utilization of the appropriate management system platform to create the content and the successful access by the end user to the published website. This paper discusses about comparative study of most widely used content management systems Joomla and Drupal. This study attempt to analyze each CMS on the basis of usage, design, performance, scalability, compatibility with different platforms, security purpose, and search engine visibility This study will help an individual or organization to choose an appropriate CMS for their specific web application.
\end{abstract}

Keywords: CMS, Joomla, Drupal

$* * *$

\section{INTRODUCTION}

The content management system provides the ability to maintain and navigate the structure of the site to the users, and allows the developer to develop the website more easily. CMSs store the data in databases to make maintaining a website less cumbersome as there are no separate files for each website page. As the content is pulled dynamically from the database it is very easy to control the placement of it on the website by setting visibility rules in advance. One of the crucial limitations of a management system is that there are numerous CMSs available as open source software and they are free to download and install. Due to this, it is becoming more and more difficult to choose and implement one particular content management system procedure for a company or an organization. The challenge in correctly implementing a CMS is both the author's utilization of the appropriate management system platform to create the content and the successful access by the end user to the published website. It is quite difficult to draw a conclusion as to which CMS is better as there are several pros and cons associated with each CMS. This study attempts to analyze CMS Joomla [1] and Drupal [2] on the basis of usage, design, performance, scalability, compatibility with different platforms, security purpose, and search engine visibility.

\section{JOOMLA}

Joomla is a class of Open Source CMSs written in PHP scripting language and uses MySQL database for the backend. Compared to Drupal, Joomla is fairly new and is gaining popularity among users because of many aspects, including ease of usability and extensibility. There are around 4500 extensions and modules available to enhance the functionality of the core Joomla package. Joomla can be installed and run on Linux, Windows or Macintosh OS. It is distributed under GPL and is free to use. Advanced components of Joomla 1.5 are built using Model-View-Controller (MVC) design pattern [3]. The standard release of Joomla contains the basic features such as blogs, RSS feeds, caching, search functionality, printable versions of pages, create and manage menus, administer the system and support for language internationalization. Joomla keeps content in its database to provide dynamic formatting. Web pages can be presented in unique format preferred by different visitors and different computers as they are not static files. Joomla templates are composed of XHTML block and in line tagged element. The theme manager interacts with data collectors and Menu manager in particular pattern. The whole system is made up of three types of pages: Sections, Categories and Articles [4]. 


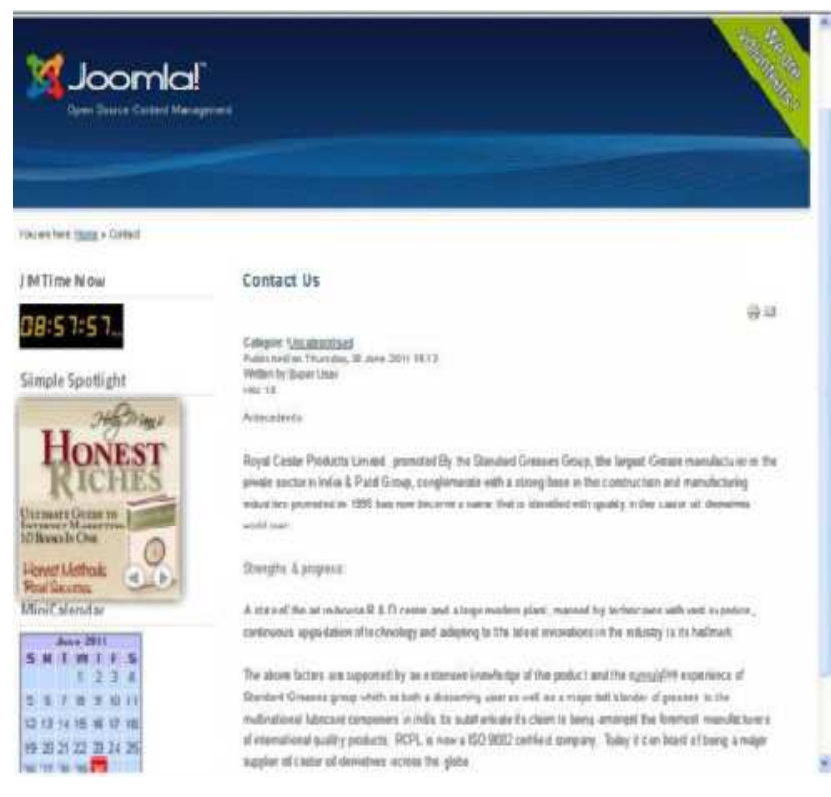

Fig-1: Joomla CMS Page.

\subsection{Joomla File Structure}

The understanding of the basics of the directories and files structure in Joomla site is essential. When Joomla is installed, there will be a default file structure either on the local machine or on the server. Below is an example showing how each folder has all the important documentation structured and organized.

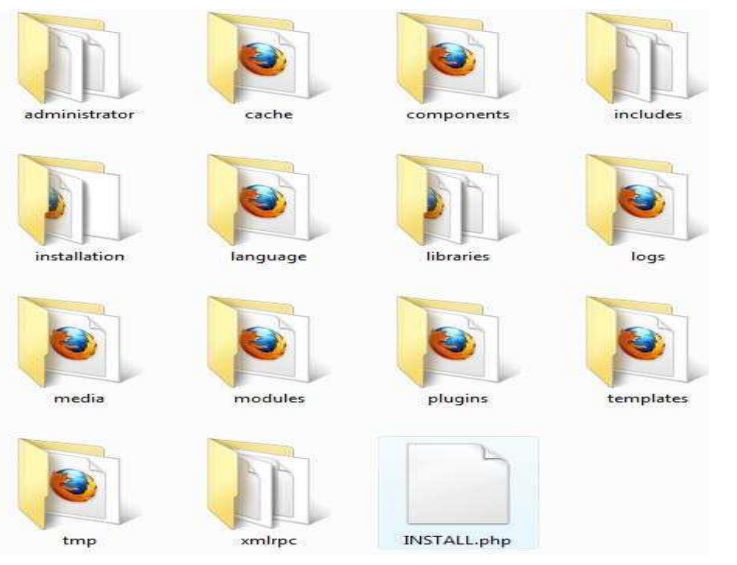

Fig-2: Joomla File Structure.

\subsection{Joomla's Key Features}

Graphical Flexibility: Many packages of graphical themes are available. It is easy to create custom themes using template files, a style sheet, a file containing information and a theme screenshot. Creating a theme from HTML page is also easy. WYSIWYG Editors: Joomla provides default editor tinyMCE which allows default video and podcast extension. Document
Manager: Joomla provides reliable document managers i.e., DocMan and RokDownload.

\subsection{Analysis of Joomla}

i) Installation: Installation of Joomla is very easy and can be installed in less than half an hour. For installation, a user doesn't require much technical knowledge - they just have to know how to connect through FTP and install databases. It can be hosted on standard shared Linux, Apache, MySQL and PHP environment.

ii) Maintenance and Update: In Joomla, maintaining and updating the site is easy. Like Drupal, Joomla users also need to backup the website before updating it. The administrator can back-up the whole website by downloading a file which contains the assets of website, and replacing the web directories using a web update interface.

iii) Community Strength and Contribution: This CMS is supported by many independent consultants and organizations in the USA. There are several books published to help learners. Forums and discussion have been started by groups where one can ask question and get answers.

iv) Usability: The user interface is very friendly with extensive use of images. Creating a new page is easy and it can be published by assigning it to the appropriate section and category.

v) Scalability: The website built on Joomla CMS can be grown as the demand for a larger site increases. Joomla is scalable and can support tens of thousands of visitors a day. Joomla's WebPages are cached for faster downloading of page and they are cached indefinitely as default but one can change the setting as needed.

vi) Web 2.0 Features: In Joomla unlike Drupal, a website administrator cannot set permissions for site visitors to comment on any content of website through core extensions, but it can be done through a plug-in. This CMS supports a simple blog but multi-author blogs are not supported. The simple blogs can be created through content administrator on the website but cannot be created through the front-end site. Therefore, blogging communities are not supported. Also, for social networking sites, a popular extension exists to create groups and content such as articles or images. It is then managed by site administrator. Outgoing RSS feeds are fully supported and add-on plugins can help in displaying other RSS feeds to the user website. However users cannot modify those feeds.

vii) Security: The updates on security are released on joomla.org and these updates occur frequently. Joomla has had only one major upgrade and it doesn't support the legacy version with security updates and fixed bugs. 
viii) User Roles and Workflow: The Joomla CMS supports three administrative roles: to create new content, to edit existing content, and to publish content. In this CMS, one cannot give permission to particular users to edit or publish based on section of website or type of content. There is no notification system in which to forward or flag content. The site based on Joomla CMS is not very flexible for many different content editors as it does not give an easy way to set up a workflow based on type of content.

\section{DRUPAL}

Drupal is an Open Source CMS written in PHP and uses MySQL, PostgreSQL or MS SQL for database. Drupal can be setup on Linux, Windows or Macintosh OS. It is distributed under GPL ("GNU General Public License") [5] and is free to download.

The architecture of Drupal is designed in such a way that the three different layers work independently and correlate with each other to give the final output. These three layers are the content which forms the website, the application algorithm that organizes this content for presentation, and the representation layer which is incorporated by the Drupal theme system. The webpage that comes to a viewer's browser goes through a sequential process in which Drupal modules take all the relevant content from the databases and then the theme gets ready for the final presentation. Unlike Joomla, Drupal's architecture does not follow the design pattern of MVC but instead follows the Presentation-AbstractionControl (PAC) [6].

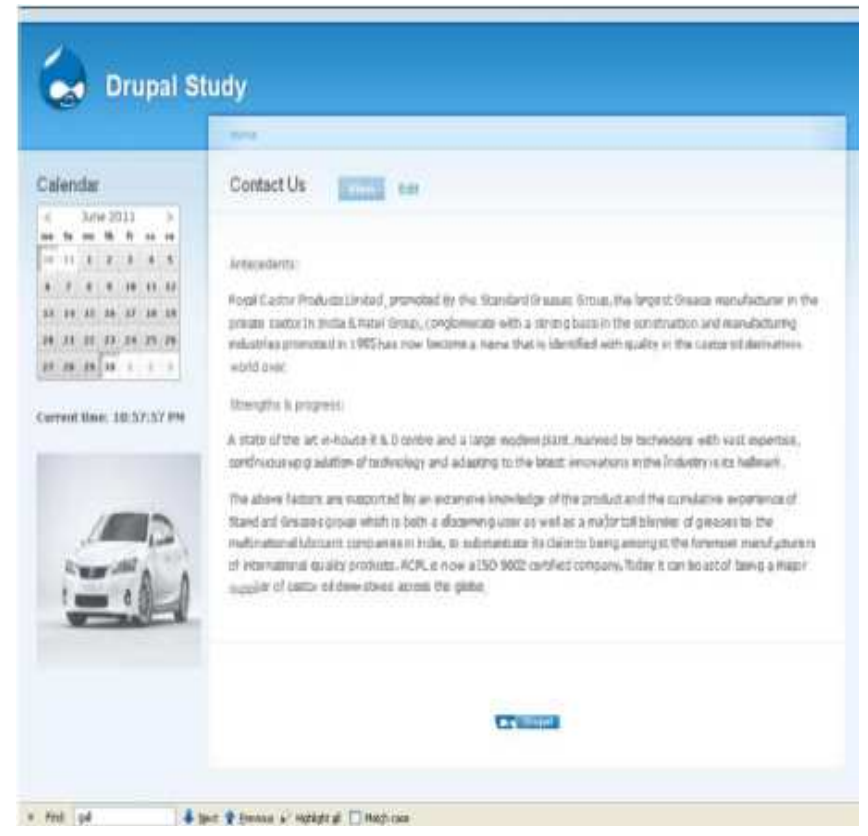

Fig-3: Drupal CMS Page.

\subsection{Drupal File Structure}

It is very essential to understand the basics of how the directories and files are structured on a Drupal site. When Drupal is installed, there will be a default file structure either on the local machine or on the server. Below is an example showing how each folder has all the important documentation structured and organized.
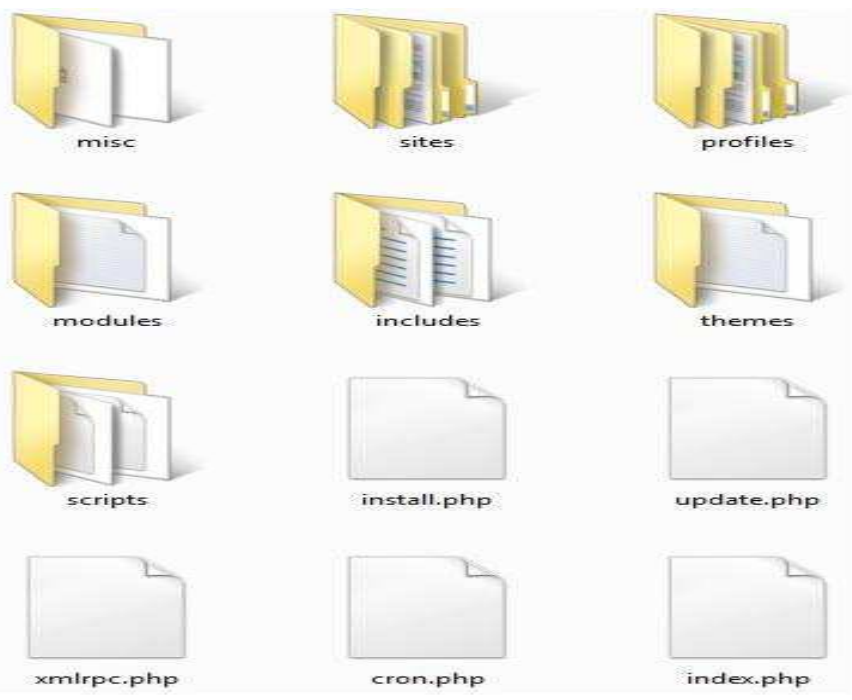

Fig-4: Drupal File Structure.

\subsection{Drupal's Key Features}

i) Advanced Control of URL: Drupal provides a precise control over URL structure. Each content item which is called node in Drupal can be given a custom URL. The path auto module can automate custom URL structure for each content type.

ii) Custom Content Types and Views: Using the Views module and the Content Construction Kit (CCK), we can create new content type without writing any code. There can be created any number of custom content types and can be displayed in many different ways. Some examples of content types are forum posts, tutorials, blog spots, news stories, classified ads, and podcasts.

iii) Themeing and PHP Template: Themeing in Drupal can be done without any PHP knowledge. Drupal uses PHP template theme engine by default.

iv) Hook System: This system in Drupal enables the user to hook in new modules easily. This hook system is invoked when any activity is done in Drupal. That action sends information to other modules which instruct them to perform a task. 
v) Filter System: This system provides control over what content should be allowed to be viewed by anonymous user and admin users. One example would be if one wants to provide HTML control to admin user and filter that from an anonymous user. This feature helps to secure the website.

\subsection{Analysis of Drupal}

i) Installation: For Drupal installation, the user does not require more technical knowledge rather than just how to connect through FTP and install databases. The installation time for the new user with knowledge of general installation of other systems might be less than half an hour.

ii) Maintenance and Update: In the Drupal CMS, maintaining and updating site is easy. The procedure for updating the website includes the backup of the website, and then replacing the files using a web update interface. By downloading only one files which contains the assets of website; administrators can back up the whole website. The database can be stored in PHPMyAdmin. Drupal gives a notice to the site admin when ever any upgrades are required. A major upgrade may affect the current template or plug-ins. Drupal also provides security updates for previous versions in case administrator doesn't want to change the version.

iii) Community Strength and Contribution: The community of Drupal is very large in terms of its users and developers. There are more than six hundred fifty thousand users and two thousand developers have signed up on Drupal.org.

iv) Usability: An administrator can easily access the page or section in visitor mode by just clicking the edit button. Accessibility to an admin area requires some learning, as its default setting does not have a refined look. The core package does not include any editor like WYIWYG (What You See is What You Get) but one can be installed as a plug-in. In Drupal editing pages or sections are the same, just while adding new page one may need to link it by hand.

v) Scalability: Drupal is highly scalable with high traffic handling capabilities. Its WebPages are cached indefinitely as the default setting configuration but can also be manually cached for a specific time. Moreover, functionality area blocks can be cached.

vi) Web 2.0 Features: Drupal is an excellent community platform provider. It outperforms all other options in this area. A website administrator can set permissions for site visitors to comment on any content of website. This feature facilitates social networking website which allows visitors to create a group. As per their set permissions, they can post content such as article, pictures, and videos which can be managed by the admin. This CMS also supports multi-author blogs and subscribed visitors can create their own blog in the blogging community. Outgoing RSS feeds are fully supported and add- on plug-ins can help in displaying others RSS feeds to user website. Moreover this RSS feed can be modified as per the requirement.

vii) Security: Security updates are published on drupal.org. It gives a notice through update status plug-in to its users whenever new update is released. Drupal's active community is very active and any security holes are remedied very quickly. There are references available to guide in making a site more secure.

viii) User Roles and Workflow: Drupal's core includes two default set of roles, anonymous user and authenticated user. Apart from these, any number of user roles can be created and assigned different permissions depending upon the content type. Add-on modules can be used to give more specific permissions to users based on content section using taxonomy function.

\section{COMPARATIVE ANALYSIS}

Table-1: Comparison of Joomla and Drupal

\begin{tabular}{|l|l|l|}
\hline $\begin{array}{l}\text { Ease of Hosting and } \\
\text { Installation }\end{array}$ & Excellent & Excellent \\
\hline $\begin{array}{l}\text { Ease of Setting up a Simple } \\
\text { Site }\end{array}$ & Solid & Solid \\
\hline $\begin{array}{l}\text { Ease of Learning to } \\
\text { Configure a More Complex } \\
\text { Site }\end{array}$ & Excellent & Solid \\
\hline Content Admin Ease of Use & Solid & Solid \\
\hline Graphical Flexibility & Excellent & Excellent \\
\hline Structural Flexiblity & Solid & Excellent \\
\hline User Roles and Workflow & Fair & Solid \\
\hline $\begin{array}{l}\text { Community/ Web 2.0 } \\
\text { Functionality }\end{array}$ & Solid & Excellent \\
\hline Extending and Integrating & Solid & Excellent \\
\hline Scability and Security & Solid & Solid \\
\hline Site Maintenance & Solid & Solid \\
\hline $\begin{array}{l}\text { Support/Community } \\
\text { Strength }\end{array}$ & Excellent & Excellent \\
\hline
\end{tabular}

\section{CONCLUSIONS}

A particular CMS may provide a better option for one application while another CMS may be more suitable for a different purpose. The study of widely used CMSs Joomla, Drupal and the analysis of the features of an individual system can help an individual or organization to choose an appropriate CMS for their specific web application. 


\section{REFERENCES}

[1] Joomla, www.joomla.org

[2] Drupal, www.drupal.org

[3] Angela Byron, Addison Berry, Jeff Eaton, Nate Haug, James Walker, and Jeff Robbin. Using Drupal. O'Reilly, December2008

[4] Joomla CMS, http://www.wilsonmar.com/joomla.htm

[5] http://www.w3schools.com/html5/default.asp

[6] http://www.w3schools.com/js/

[7] http://drupal.org/documentation/customization/tutorials

[8] http://www.joomla.org

[9] Tessa Blakeley Silver, Joomla! 1.5 Template Design,Packt

Publishing Lt. Birmingham, Mumbai.

[10] Drupal Handbooks 2009, http://drupal.org/handbooks.

\section{BIOGRAPHIES}

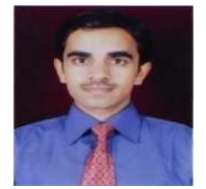

Mr. Bhushan Wakode is Assistant Professor in Information Technology Department of Government College of Engineering Amravati. He has completed his Bachelors and Masters degree in Computer Science and Engineering. He has over Ten Years of experience in teaching. His research interest includes Mobile Computing and Network Security.

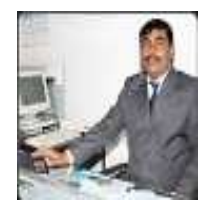

Dr.D.N.Choudhary is Professor \& Head of Department of Computer Science \& Engineering at Jawaharlal Darda Institute of Engineering \& Technology, Yavatmal. He has completed his Master of Engineering in Computer Science \& Engineering and Ph.D in Computer Science. He is Ph.D supervisor in Computer Sci. \& Engineering at SGB Amravati University, Amravati (Maharashtra)-INDIA and member of various National \& International technical Institutions like ISTE, IEI etc .He has published many research papers in various National, International reputed Journals. 